Article

\title{
Research on Stator Main Insulation Temperature Field of Air-Cooled Turbo-Generator after Main Insulation Shelling
}

\author{
Weili Li ${ }^{1}$, Yong Li ${ }^{1,2}$, Ying Su ${ }^{1, *(D)}$, Purui Wang ${ }^{1}$ and Wenmao Liu ${ }^{1}$ \\ 1 Electric Engineering, Beijing Jiaotong University, Beijing 100044, China; li.weili@yeah.net (W.L.); \\ 13621268564@139.com (Y.L.); 13117389@bjtu.edu.cn (P.W.); 16117380@bjtu.edu.cn (W.L.) \\ 2 Beijing BEIZHONG Steam Turbine Generator Co., Ltd., Beijing 100040, China \\ * Correspondence: yasarusa@163.com; Tel.: +86-105-168-4059
}

Received: 16 February 2018; Accepted: 20 April 2018; Published: 30 April 2018

\begin{abstract}
The stator main insulation is the key component of turbo-generator, which is related to the thermal aging of turbo-generator. It is vital to accurately judge the generator aging by calculating the temperature distribution under main insulation normal operation and fault operation. In this paper, taking a $150 \mathrm{MW}$ air-cooled turbo-generator as an example, the temperature field of the main insulation was studied after the stator main insulation shelling. Based on the finite element method, the stator temperature field after the main insulation shelling was calculated. The main insulation position of maximum temperature drop and the temperature distribution of the stator main insulation along the circumference and the axial direction were analyzed. At the same time, with the shelling gap of main insulation increases, the temperature distribution between shelling gap $\delta=0.5 \mathrm{~mm}$ and $\delta$ $=1.0 \mathrm{~mm}$ was compared. The results can provide a theory for fault monitoring and diagnostics of the large-scale turbine generator.
\end{abstract}

Keywords: turbine generator; temperature field; main insulation shelling

\section{Introduction}

Under the influence of electric, thermal, vibration and mechanical stresses, the stator and rotor main insulation of the generator may be caused serious faults such as aging, shelling and discharging. Many specialists make researches about generator insulation failure mechanism, discharging and fault monitoring after insulation aging [1-10]. Dr. H. Zhu and C. Morton made a detailed research on the diagnosis about thermal aging of stator windings [11,12]. It can be defined that main insulation occurs delamination and shelling by evaluating the insulation conditions after thermal cycling test. Dr. Greg C. Stone made a comprehensive research on electrical insulation for rotating machines, especially in design, evaluation, aging, testing and repair [13-17]. However, the insulation temperature distribution after insulation aging is still the effective way to evaluate insulation fault of machines. Therefore, a $150 \mathrm{MW}$ air-cooled turbo-generator is taken as an example to study the stator main insulation temperature field of the air-cooled turbo-generator after the main insulation shelling in this paper, which can provide a theory for the diagnosis of the generator after the fault operation.

\section{Stator Calculation Model of Turbo-Generator}

\subsection{Basic Parameters and Physical Model of Air-Cooled Turbine Generator}

According to the fault statistics of the stator main insulation from the power plant, the generator main insulation occur shelling with shelling gap less than $1.0 \mathrm{~mm}$. Once the main insulation shelling 
gap surpass $1.0 \mathrm{~mm}$, the generator will stop running. A broken bar of a $150 \mathrm{MW}$ air-cooled generator is shown in Figure 1. Thus, a 150 MW air-cooled turbo-generator is taken as an example to study the stator temperature field under the main insulation shelling and given the relevant parameters, as shown in Table 1.

A broken bar of the 150MW generator
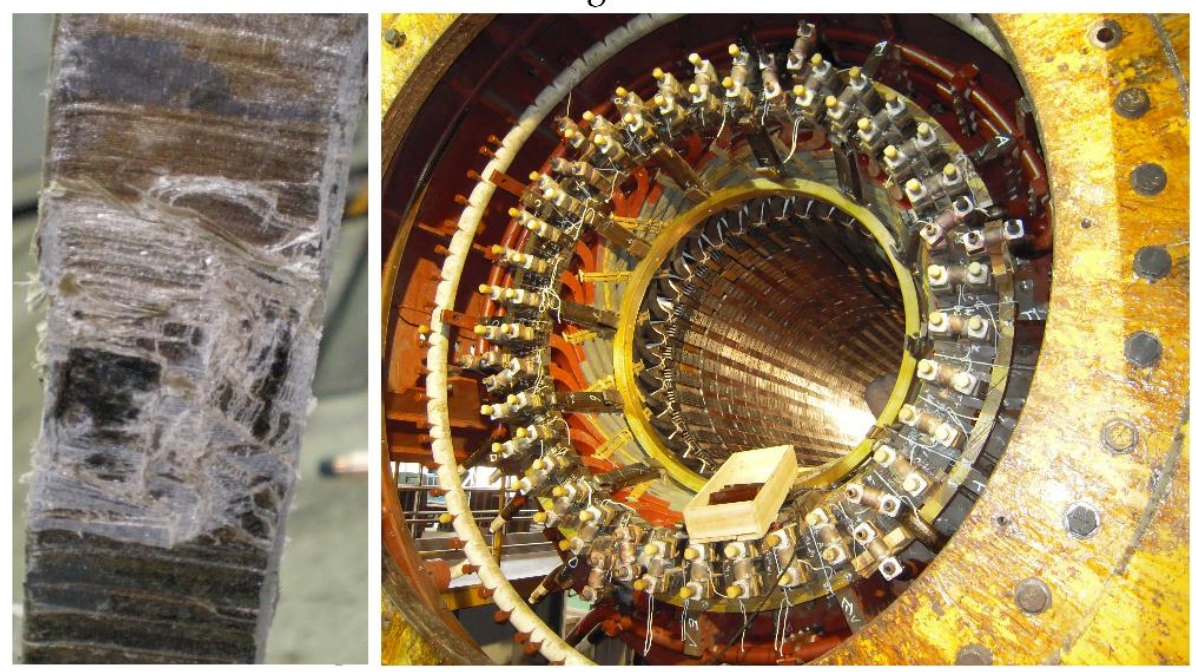

Figure 1. The photo of a broken bar of the $150 \mathrm{MW}$ turbine generator.

Table 1. Generator basic data.

\begin{tabular}{lcccccc}
\hline Main Data & Power (W) & Voltage (V) & Current (A) & Rotating Speed (r/min) & Frequency (Hz) & Power Factor \\
\hline Rated data & 150 & 15,750 & 6469 & 3000 & 50 & 0.85 \\
\hline
\end{tabular}

Due to the symmetry of wind path of the generator and the generator structure in the circumferential direction, the calculation model is chosen to calculate one tooth pitch in the circumferential direction and two half of the stator core in the axial direction, as shown in Figure 2.

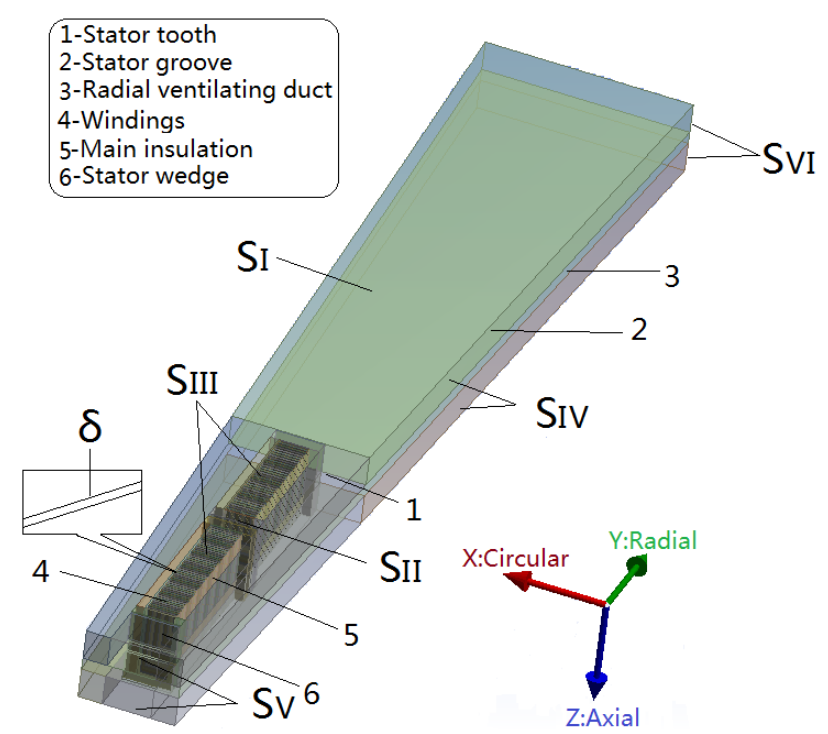

Figure 2. Stator temperature field calculation model and boundary conditions. 
In Figure 2, the rotor rotation direction is defined as the circumferential direction, denoted by $\mathrm{X}$; the direction from slot opening to base is defined as radial, denoted by $\mathrm{Y}$; the direction from the turbine end to the exciter end is defined as the axial direction, denoted by $\mathrm{Z}$.

\subsection{D Mathematical Model of Temperature Field of Turbo-Generator Stator}

In order to calculate stator temperature field of the air-cooled turbine generator, the 3D temperature field mathematical model is set up by the following equations [18]:

The 3D heat transfer equation in the calculation domain:

$$
\frac{\partial}{\partial x}\left(\lambda_{x} \frac{\partial T}{\partial x}\right)+\frac{\partial}{\partial y}\left(\lambda_{y} \frac{\partial T}{\partial y}\right)+\frac{\partial}{\partial z}\left(\lambda_{z} \frac{\partial T}{\partial z}\right)=-q \quad(x, y, z) \in \Omega
$$

where $\lambda_{x}, \lambda_{y}, \lambda_{z}$ are the thermal conductivity along $x, y$, and $z$ axes, respectively, $T$ is temperature, $q$ is the heat density, $\Omega$ is solving domain

The law of air flow in the calculation domain abides by the following equations:

Mass conservation equation:

$$
\nabla\left(\rho v_{r}\right)=0
$$

Momentum conservation equation:

$$
\nabla\left(x \rho v_{r}^{2}\right)+\rho\left(2 w \times v_{r}+w \times w \times r\right)=-\nabla p+\nabla \tau+F
$$

Energy conservation equation:

$$
\frac{\partial(x \rho T)}{\partial t}+\operatorname{div}(\rho v T)=\operatorname{div}\left(\frac{\lambda}{c} \operatorname{grad} T\right)+S_{r}
$$

where $\rho$ is mass density, $v_{r}$ is the relative velocity vector, $r$ is position vector of micro cell in rotating coordinate system, $p$ is static pressure acting on micro cell in air, $\tau$ is viscous stress in infinitesimal surface generated by molecular viscosity effects, $\rho\left(2 w \times v_{r}+w \times w \times r\right)$ is Coriolis force, $w$ is angular velocity, $F$ is volume force on micro cell, $v$ is absolute speed, $\lambda$ is thermal conductivity, $c$ is specific heat in constant pressure, $S_{r}$ is the ratio of the heat generated in the unit volume and $c$.

Since the fluid in the stator calculation domain is turbulent flow, standard $k-\varepsilon$ model is used to simulate turbulence equation:

$$
\left\{\begin{array}{l}
\frac{\partial\left(\rho_{f} k\right)}{\partial t}+\operatorname{div}\left(\rho_{f} k V\right)=\operatorname{div}\left[\left(u+\frac{u_{t}}{\sigma_{k}}\right) g r a d k\right]+G_{k}-\rho_{f} \varepsilon \\
\frac{\partial\left(\rho_{f} \varepsilon\right)}{\partial t}+\operatorname{div}\left(\rho_{f} V \varepsilon\right)=\operatorname{div}\left[\left(u+\frac{u_{t}}{\sigma_{\varepsilon}}\right) g r a d \varepsilon\right]+G_{1 \varepsilon} \frac{\varepsilon}{k} G_{k}-G_{2 \varepsilon} \rho_{f} \frac{\varepsilon^{2}}{k}
\end{array}\right.
$$

where $k$ is the turbulent kinetic energy, $\varepsilon$ is the diffusion factor; $\rho_{f}$ is the fluid density, $V$ is the velocity vector of fluid; $t$ is the time, $G_{k}$ is turbulent generation rate, $u_{t}$ is turbulent viscosity coefficient, $G_{1 \varepsilon}$ and $G_{2 \varepsilon}$ are constant; $\sigma_{k}$ and $\sigma_{\varepsilon}$ are respectively the equation $k$ and equation $\varepsilon$ of Planck's constant turbulence.

\subsection{Calculation Model of 3D Temperature Field of Turbo-Generator Stator}

The boundary condition of calculation model of $3 \mathrm{D}$ temperature field of turbo-generator stator $[19,20]$ :

(1) $S_{\mathrm{I}}, S_{\mathrm{II}}, S_{\mathrm{III}}$ and $S_{\text {IV }}$ are adiabatic surfaces, which satisfy:

$$
\frac{\partial T}{\partial n}=0
$$


(2) Tooth top $S_{\mathrm{V}}$ and Yoke back $S_{\mathrm{VI}}$ are heat transfer surfaces, which satisfy:

$$
-\lambda \frac{\partial T}{\partial n}=\alpha\left(T-T_{f}\right)
$$

where $n$ is normal vector of surface, $\lambda$ is heat transfer coefficient, $T_{f}$ is ambient temperature.

(3) The outlet port of stator radial ventilating duct is set a standard atmospheric pressure condition. The inlet air velocity of stator ventilating duct is 15.8 , which is calculated by air volume of rotor outlet port and air gap, while the inlet air temperature of the stator ventilating duct is $68^{\circ} \mathrm{C}$ which is defined by outlet air temperature of rotor ventilating duct.

According to solving domain and boundary conditions provided by Figure 1, as well as the above theoretical equation, the $3 \mathrm{D}$ temperature field mathematical calculation model is solved by using fluid-solid coupled method, and the temperature field can be determined.

\section{Main Insulation Temperature Field Calculation Results and Analysis of Air-Cooled Turbo-Generator Stator}

By fluid-solid coupled method, the stator temperature field under the main insulation normal operation and fault operation is obtained. The computed results in the temperature measurement point of the normal case, which is $133^{\circ} \mathrm{C}$, are almost the same with the measured value $131^{\circ} \mathrm{C}$, which indicates that the calculation method is correct.

\subsection{Research on the Influence of Stator Main Insulation Shelling on Main Insulation Temperature Drop}

For convenience of illustration and analysis, the left and right sides of upper main insulation are defined as $U P_{2}$ and $U P_{3}$, and the top and bottom sides of the main insulation are defined as $U P_{1}$ and $U P_{4}$. The same rules are used to define the lower main insulation as $D N_{1}-D N_{4}$. The insulation shelling positions in the calculation model are located at $U P_{2}$ and $D N_{2}$, as shown in Figure 2.

By solving the above fluid-solid coupling heat transfer equation, the upper and lower main insulation maximum temperature drop value can be obtained, as shown in Table 2.

Table 2. The calculation results of the stator insulation temperature drop.

\begin{tabular}{|c|c|c|c|c|c|c|c|c|}
\hline $\begin{array}{ll}\text { TEMP. }\left({ }^{\circ} \mathrm{C}\right) & \text { Position } \\
\end{array}$ & $U P_{1}$ & $U P_{2}$ & $U P_{3}$ & $U P_{4}$ & $D N_{1}$ & $D N_{2}$ & $\mathrm{DN}_{3}$ & $D N_{4}$ \\
\hline $\begin{array}{l}\text { Normal } \\
\text { operation }\end{array}$ & 31.95 & 40.35 & 40.35 & 6.66 & 13.79 & 26.31 & 26.31 & 17.83 \\
\hline Shelling $0.5 \mathrm{~mm}$ & 35. & 25.1 & 47 & 8.9 & 10. & 21.72 & 3 & 18.7 \\
\hline Shelling $1.0 \mathrm{~mm}$ & 36.61 & 19.79 & 50.01 & 11 & 13.74 & 13.88 & 39.44 & 24.64 \\
\hline
\end{tabular}

In Table 2 and Figure 3, the positions of maximum temperature drop of the main insulation are in the same radial height of the left side $U P_{2}$ and the right side $U P_{3}$ and the values of maximum temperature drop are basically the same due to the stator circumferential symmetry of the air-cooled turbine generator in normal operation. The maximum temperature drop law of the lower main insulation left side $D N_{2}$ and right side $D N_{3}$ is similarly with the upper main insulation $U P_{2}$ and $U P_{3}$. The position of maximum temperature drop of $D N_{2}$ and $D N_{3}$ is in the central of the lower main insulation in the radial direction and the value is less than the $U P_{2}$ and $U P_{3}$.

As also shown in Table 2 and Figure 2, compared with the positions and values of the maximum temperature drop in the upper main insulation $U P_{1}, U P_{4}$ and the lower main insulation $D N_{1} D N_{4}$, their positions are basically same circumferential direction and the value of $U P_{1}$ is the largest. There are two main reasons: (1) $U P_{1}$ is located on the upper bar, due to the impact of additional loss, the total loss of upper bar is larger than that of lower bar. (2) $U P_{1}$ close to the side of the generator air gap, and the heat transfer condition is good. However, interlayer insulation between the $U P_{4}$ and the 
$D N_{1}$, and $D N_{4}$ close to the yoke core have poor heat transfer conditions, which cause the insulation temperature drop smaller than $U P_{1}$.

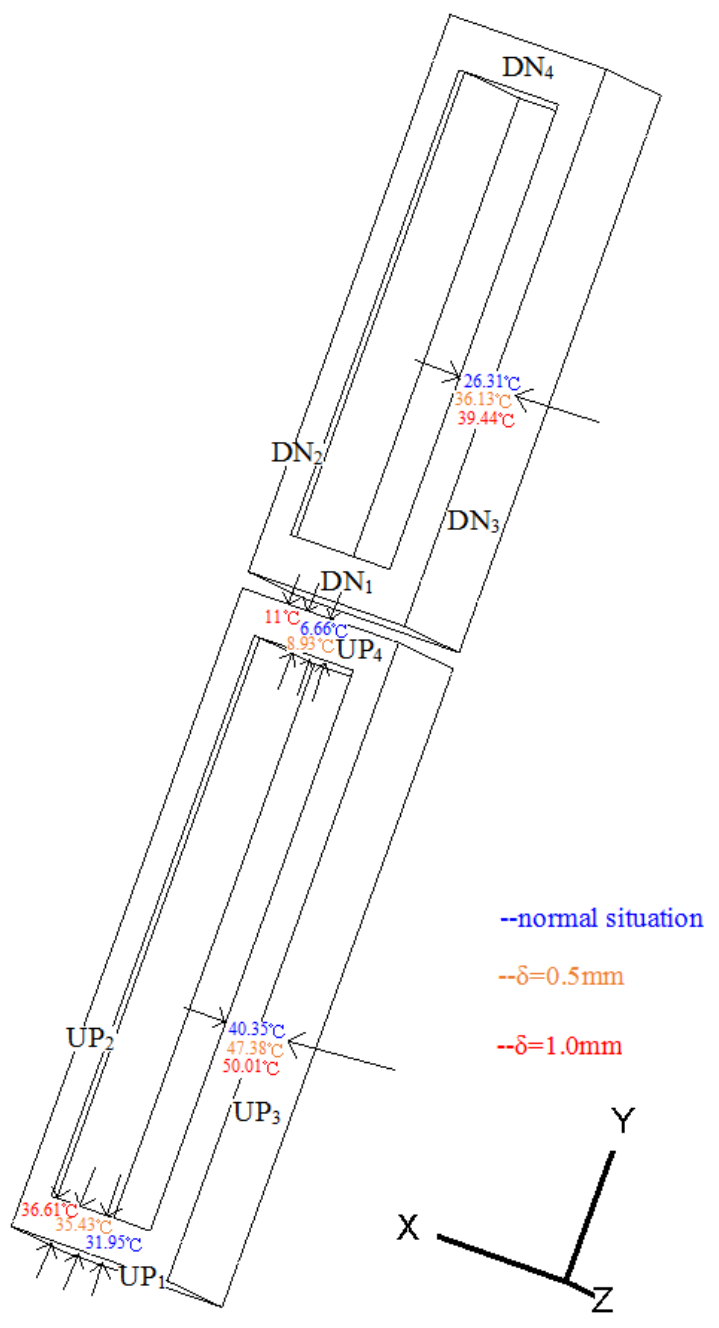

Figure 3. The position definition of stator main insulation and the maximum temperature drop in three cases.

From Table 2, in the cases of the stator main insulation $\left(U P_{2}\right.$ and $\left.D N_{2}\right)$ unilateral shelling $\delta=0.5 \mathrm{~mm}$, the position of maximum temperature drop of the main insulation appears on $U P_{3}$, which rises $7{ }^{\circ} \mathrm{C}$ than that of the normal conditions and locates at the radial height of $Y=47.5 \mathrm{~mm}$, as same as the radial height of the normal operation. However, the position of the maximum temperature drop in the top side of the upper insulation $U P_{1}$ and the bottom side $U P_{4}$ in the circumferential direction is offset $4 \mathrm{~mm}$ to the shelling side, and the values of maximum temperature drop is also increased.

Moreover, the maximum temperature drop of the main insulation is located on $\mathrm{UP}_{3}$ and the value is increasing in the case of $\delta=0.5 \mathrm{~mm}$, which is because that the heat inside the upper bar is difficult to transfer from $U P_{2}$ to the stator tooth considering the air of the shelling gap in $U P_{2}$. At the same time, the temperature of the tooth close to $U P_{3}$ changes little, so the maximum temperature drop of the un-shelling side also increases.

Similarly, in the case of main insulation of the lower bar $D N_{2}$ shelling $\delta=0.5 \mathrm{~mm}$, the maximum temperature drop appears on the $D N_{3}$, which is $9.8^{\circ} \mathrm{C}$ higher than that in the normal operation, and its radial position at the height $Y=160.5 \mathrm{~mm}$, which is same as the normal operation. In addition, the maximum temperature drop of $D N_{2}$ is $3.4^{\circ} \mathrm{C}$ lower than $U P_{2}$, while it is about $4.6{ }^{\circ} \mathrm{C}$ lower than $D N_{2}$ at normal operation. 
With the same analysis method, in the case of the stator main insulation $\left(U P_{2}\right.$ and $\left.D N_{2}\right)$ unilateral shelling $\delta=1.0 \mathrm{~mm}$, the maximum temperature drop on $U P_{3}$ and $D N_{3}$ are respectively $9.7^{\circ} \mathrm{C}$ and $13.1^{\circ} \mathrm{C}$ higher than that of the normal operation, and their radial position is respectively also at the height $\mathrm{Y}=47.5 \mathrm{~mm}$ and $\mathrm{Y}=160.5 \mathrm{~mm}$. In addition, the maximum temperature drop of $\mathrm{DN}_{2}$ is $5.9^{\circ} \mathrm{C}$ lower than that of $U P_{2}$, and is about $12.4{ }^{\circ} \mathrm{C}$ lower than $D N_{2}$ at normal operation.

\subsection{Research on the Main Insulation Temperature Distribution in the Axis-Radial Section under Main Insulation Normal Operation and Fault Operation}

The law of the maximum temperature drop of the stator main insulation is studied under main insulation normal and fault operation above. The main insulation temperature distribution of the stator windings in the axial direction is uneven due to the presence of the stator radial ventilation duct. Therefore, it is necessary to study the temperature distribution of stator main insulation in the axis-radial section under main insulation normal and unilateral shelling operation.

For convenience of analysis, the main insulation $U P_{2}$ and $D N_{2}$ of upper and lower stator winding along the circumference direction are divided into three equal parts, $P_{1}, P_{2}, P_{3}, P_{4}$, where $P_{1}$ is close to the stator windings and $P_{4}$ is close to the stator teeth core. The $P_{1} \sim P_{4}$ temperature field in the normal operation are shown in Figure $4 \mathrm{a}-\mathrm{d}$ below.

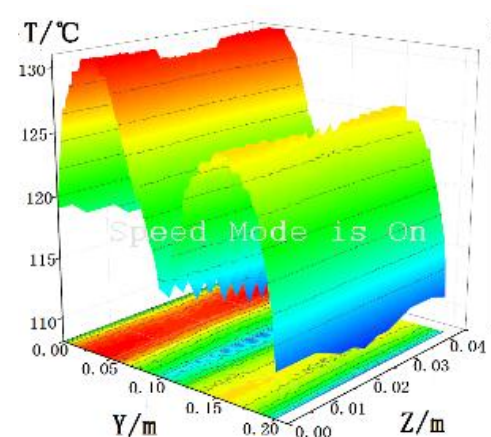

(a)

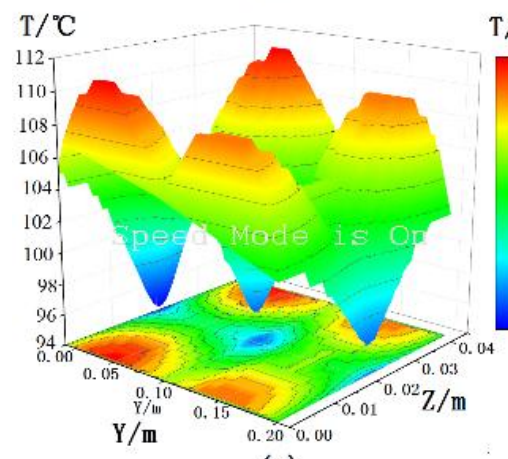

(c)

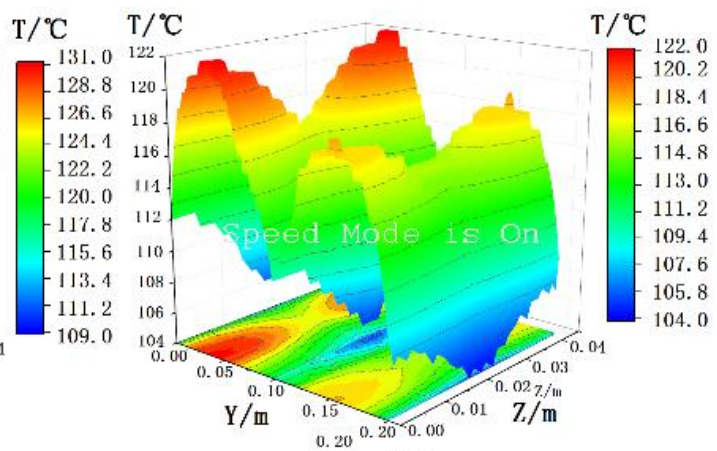

(b)

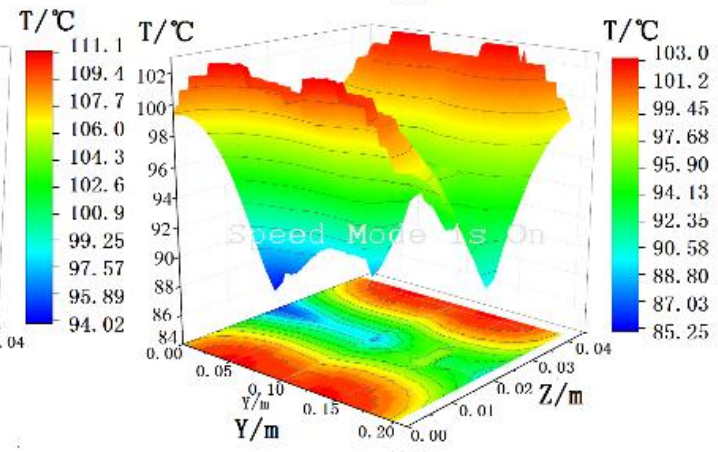

(d)

Figure 4. The main insulation axis-radial section temperature distribution under normal operating of the generator: (a) The main insulation axial-radial $P_{1}$ temperature distribution; (b) The main insulation axial-radial $P_{2}$ temperature distribution; (c) The main insulation axial-radial $P_{3}$ temperature distribution; (d) The main insulation axial-radial $P_{4}$ temperature distribution.

In Figure 4, the maximum temperature of the main insulation of the upper bar is on the surface $P_{1}$, and the temperature value is $131^{\circ} \mathrm{C}$, where the radial height is $\mathrm{Y}=46.5 \mathrm{~mm}$ and the axial length is $\mathrm{Z}=0$. The maximum temperature of the main insulation of the lower bar is also on $P_{1}$, the temperature is $126{ }^{\circ} \mathrm{C}$, at $\mathrm{Y}=160.5 \mathrm{~mm}, \mathrm{Z}=0$. The maximum insulation temperature of the upper bar is $5{ }^{\circ} \mathrm{C}$ higher than the lower bar.

The maximum and minimum temperature on the $P_{1}-P_{4}$ values are shown in Table 3 below. 
Table 3. The maximum and minimum temperature on $P_{1}-P_{4}$.

\begin{tabular}{ccccc}
\hline & \multicolumn{2}{c}{ Upper Main Insulation } & \multicolumn{2}{c}{ Lower Main Insulation } \\
\cline { 2 - 5 } & $\begin{array}{c}\text { Maximum } \\
\text { Temperature }\left({ }^{\circ} \mathrm{C}\right)\end{array}$ & $\begin{array}{c}\text { Minimum } \\
\text { Temperature }\left({ }^{\circ} \mathbf{C}\right)\end{array}$ & $\begin{array}{c}\text { Maximum } \\
\text { Temperature }\left({ }^{\circ} \mathrm{C}\right)\end{array}$ & $\begin{array}{c}\text { Minimum } \\
\text { Temperature }\left({ }^{\circ} \mathrm{C}\right)\end{array}$ \\
\hline$P_{1}$ & 131 & 108 & 126 & 111 \\
$P_{2}$ & 122 & 105 & 119 & 104 \\
$P_{3}$ & 111 & 94.2 & 109 & 95.9 \\
$P_{4}$ & 103 & 85.3 & 103 & 89.7 \\
\hline
\end{tabular}

In the case of the main insulation unilateral shelling $\delta=0.5 \mathrm{~mm}$, the shelling side $P_{5}-P_{8}$ main insulation axis-radial section temperature distribution is as follows. Similarly, $P_{5}$ near the stator winding, $P_{8}$ near the stator teeth core.

In Figure 5, in the case of the stator main insulation unilateral shelling $\delta=0.5 \mathrm{~mm}$, the maximum temperature of the upper main insulation is on the surface $P_{5}$, and its value is $119{ }^{\circ} \mathrm{C}$, where the radial height is $Y=46.5 \mathrm{~mm}$ and the axial length is $Z=0$; and the minimum temperature is $83.2^{\circ} \mathrm{C}$ at a position where is $Y=0, Z=21 \mathrm{~mm}$. The maximum temperature of the lower main insulation is also on $P_{5}$, the temperature value is $117^{\circ} \mathrm{C}$, at $\mathrm{Y}=160.5 \mathrm{~mm}, \mathrm{Z}=0$; and the minimum temperature value is $91.6{ }^{\circ} \mathrm{C}$ at a position where is $\mathrm{Y}=226 \mathrm{~mm}, \mathrm{Z}=21 \mathrm{~mm}$. Compared with the temperature distribution under normal operation of the main insulation, the maximum temperature in the shelling side decreases, but the location is not changed, indicating that the air in the shelling gap prevent the heat transfer to the shelling side of main insulation.

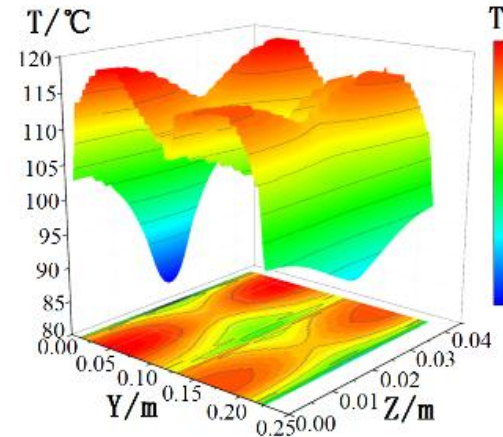

(a)

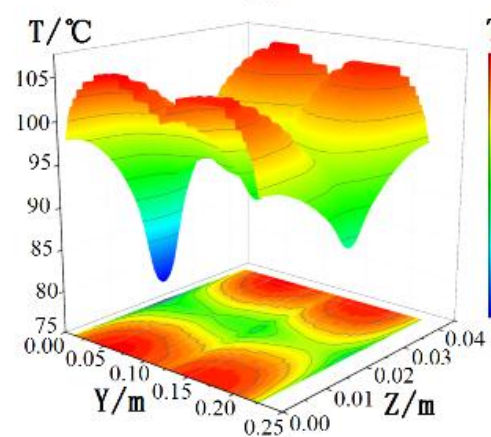

(c)

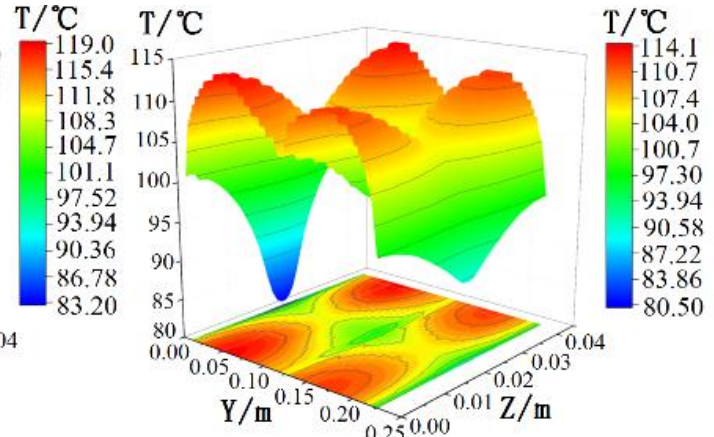

(b)

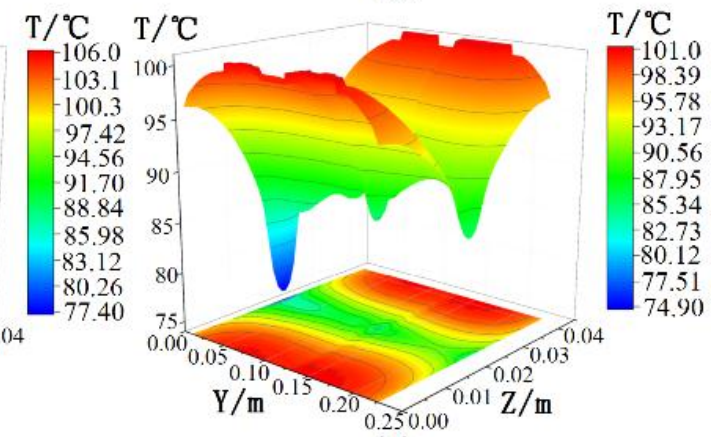

(d)

Figure 5. In the case of the stator main insulation unilateral shelling $\delta=0.5 \mathrm{~mm}$, the main insulation axis-radial temperature distribution in the shelling side: (a) The main insulation axial-radial $P_{5}$ temperature distribution; (b) The main insulation axial-radial $P_{6}$ temperature distribution; (c) The main insulation axial-radial $P_{7}$ temperature distribution; (d) The main insulation axial-radial $P_{8}$ temperature distribution. 
From Figure 5 and Table 4, it can be seen that the temperature distribution of $P_{5}-P_{8}$ is completely different. The main insulation temperature close to core is relatively low, and the maximum temperature difference between the upper and lower main insulation temperature close to the core side is very small, which is due to the fact that the core is a very important heat transfer path. Therefore, the maximum and minimum values of the $P_{8}$ surface are smaller than that of the other three surfaces.

Table 4. The maximum and minimum temperature on $P_{5}-P_{8}$.

\begin{tabular}{ccccc}
\hline & \multicolumn{2}{c}{ Upper Main Insulation } & \multicolumn{2}{c}{ Lower Main Insulation } \\
\cline { 2 - 5 } & $\begin{array}{c}\text { Maximum } \\
\text { Temperature }\left({ }^{\circ} \mathrm{C}\right)\end{array}$ & $\begin{array}{c}\text { Minimum } \\
\text { Temperature }\left({ }^{\circ} \mathrm{C}\right)\end{array}$ & $\begin{array}{c}\text { Maximum } \\
\text { Temperature }\left({ }^{\circ} \mathrm{C}\right)\end{array}$ & $\begin{array}{c}\text { Minimum } \\
\text { Temperature }\left({ }^{\circ} \mathrm{C}\right)\end{array}$ \\
\hline$P_{5}$ & 119 & 83.2 & 117 & 91.6 \\
$P_{6}$ & 114 & 80.5 & 112 & 90.2 \\
$P_{7}$ & 106 & 77.4 & 105 & 87.8 \\
$P_{8}$ & 101 & 74.9 & 101 & 85 \\
\hline
\end{tabular}

In order to analyze the temperature distribution of the main insulation on the un-shelling side, similarly, the upper and lower main insulations $U P_{3}, D N_{3}$ are divided into three equal parts, $P_{9}-P_{12}$. Correspondingly, the temperature distribution of $P_{9}-P_{12}$ is shown in Figure 5a-d).

From Figure 6, the temperature distribution in the main insulation un-shelling side is different from the shelling side of the main insulation. In Figure 6a, the maximum temperature of the upper main insulation is on the surface $P_{9}$, which is $140{ }^{\circ} \mathrm{C}$, and the minimum temperature value is $85.1^{\circ} \mathrm{C}$, while the maximum temperature of the lower main insulation is also on $P_{9}$, which is $134^{\circ} \mathrm{C}$, and the minimum temperature value is $92.7^{\circ} \mathrm{C}$. The temperature difference (the difference between the maximum and the minimum) of the upper insulation is $55^{\circ} \mathrm{C}$, while the temperature difference of the lower insulation is $41.3^{\circ} \mathrm{C}$. The temperature distribution position is consistent with the previous chapter.

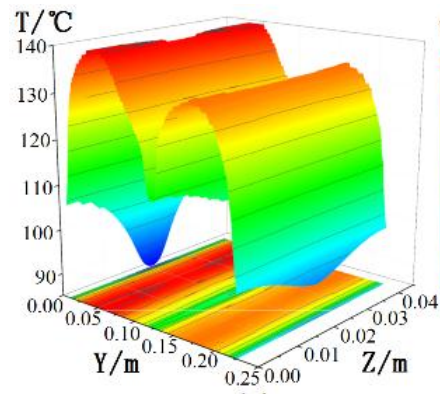

(a)

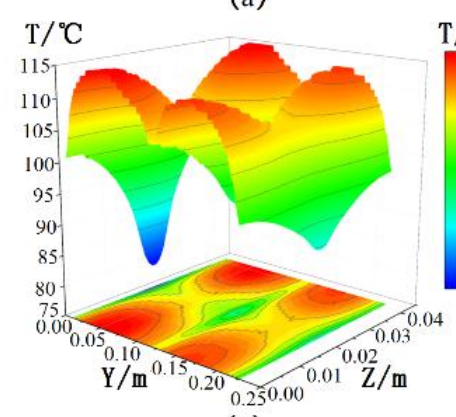

(c)

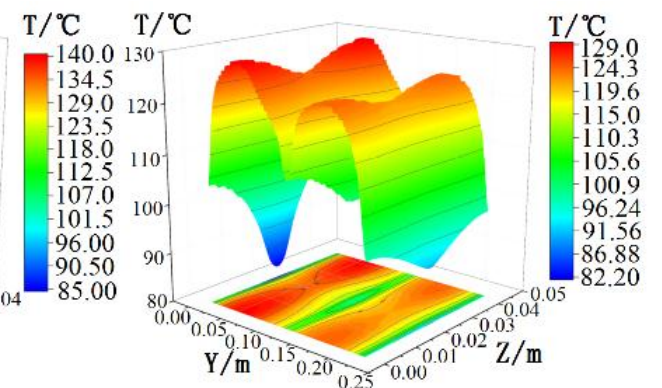

(b)

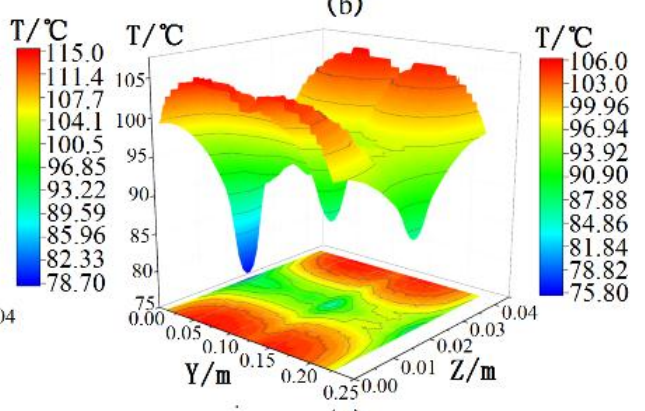

(d)

Figure 6. The main insulation axis-radial temperature distribution in the un-shelling side in the stator main insulation unilateral shelling $\delta=0.5 \mathrm{~mm}$ : (a) The main insulation axial-radial $P_{9}$ temperature distribution; (b) The main insulation axial-radial $P_{10}$ temperature distribution; (c) The main insulation axial-radial $P_{11}$ temperature distribution; (d) The main insulation axial-radial $P_{12}$ temperature distribution. 
From Figure $6 b, c$, the value of the maximum temperature and minimum temperature in the un-shelling side $P_{10}$ and $P_{11}$ are bigger than those of the shelling side $P_{6}$ and $P_{7}$ in the case of the main insulation shelling $\delta=0.5 \mathrm{~mm}$, but the temperature distribution is basically same.

In Figure $6 \mathrm{~d}$, the minimum temperature of surface $P_{12}$ close to the core side is substantially same as the minimum temperature of $P_{8}$, but the maximum temperature is $5{ }^{\circ} \mathrm{C}$ higher than that of $P_{8}$. This is because that the thermal conductivity coefficient of air in the shelling gap is much smaller than the thermal conductivity coefficient of the main insulation. Most of the loss generated by stator winding is passed through the un-shelling main insulation, causing that the main insulation temperature of the un-shelling side is higher than that of the shelling side, and the temperature of the core is slightly increased.

If the main insulation of the stator is further thermal aging from the unilateral shelling $\delta=0.5 \mathrm{~mm}$ to unilateral shelling $\delta=1.0 \mathrm{~mm}$, it will further cause the temperature value inside the main insulation rise, and the calculation results are shown in Figure 7. The main insulation temperature distribution of axis-radial surfaces $P_{13}-P_{16}$ is obtained in Figure 7.

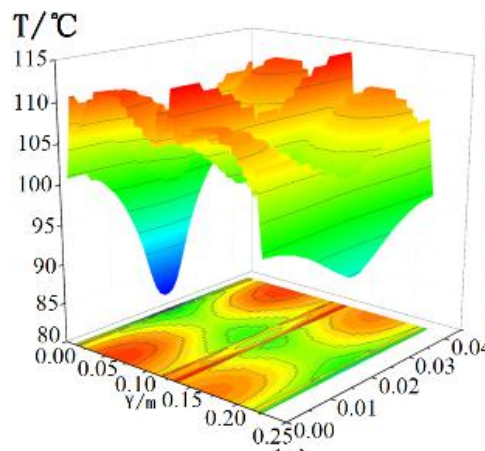

(a)

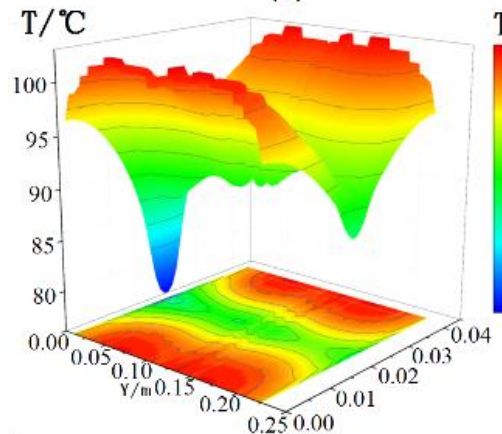

(c)

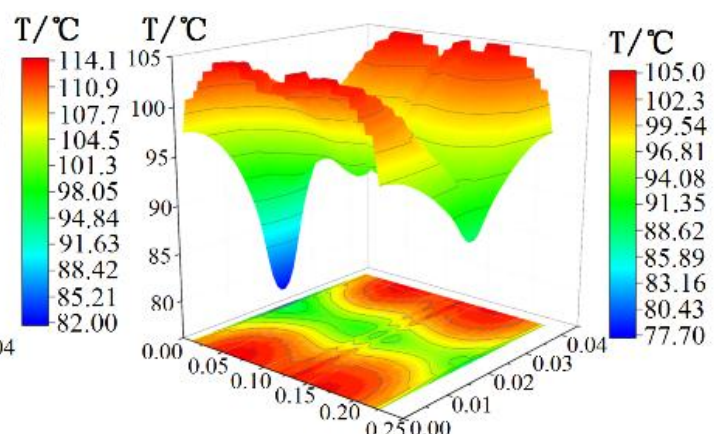

(b)

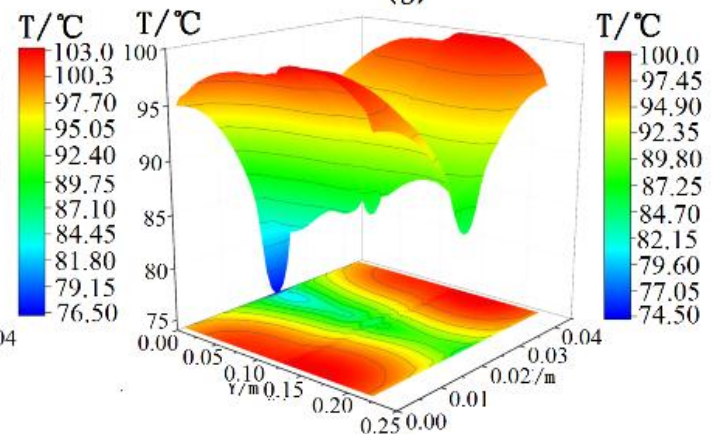

(d)

Figure 7. In the case of the stator main insulation unilateral shelling $\delta=1.0 \mathrm{~mm}$, the main insulation axis-radial temperature distribution in the shelling side: (a) The main insulation axial-radial $P_{13}$ temperature distribution; (b) The main insulation axial-radial $P_{14}$ temperature distribution; (c) The main insulation axial-radial $P_{15}$ temperature distribution; (d) The main insulation axial-radial $P_{16}$ temperature distribution.

From Figure 7a, it can be found that the temperature values of main insulation reduce compared with the temperature values of $P_{5}$. With the larger shelling gap, heat generated by stator windings is more difficult to pass through the shelling side insulation, part of the heat pass through the inter-layer insulation.

In Figure $7 \mathrm{~b}-\mathrm{d}$, compared with the stator main insulation unilateral shelling $\delta=0.5 \mathrm{~mm}$, the temperature in the $\delta=1.0 \mathrm{~mm}$ shelling side is relatively lower, and the temperature difference is also smaller. The shelling gap undertakes most of the main insulation temperature drop, resulting in heat transfer capacity of the main insulation shelling side decreases. 
Similarly, Figure 8 is the axis-radial temperature distribution in the main insulation un-shelling side in the case of unilateral shelling $\delta=1.0 \mathrm{~mm}$.

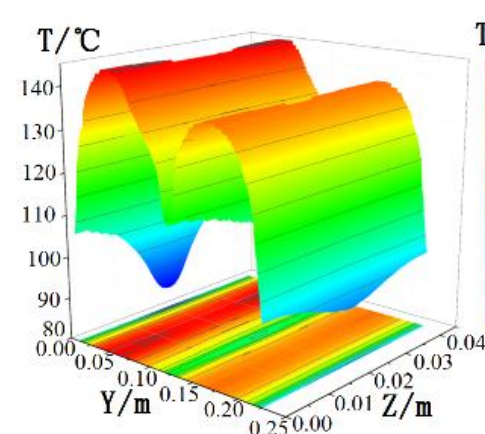

(a)

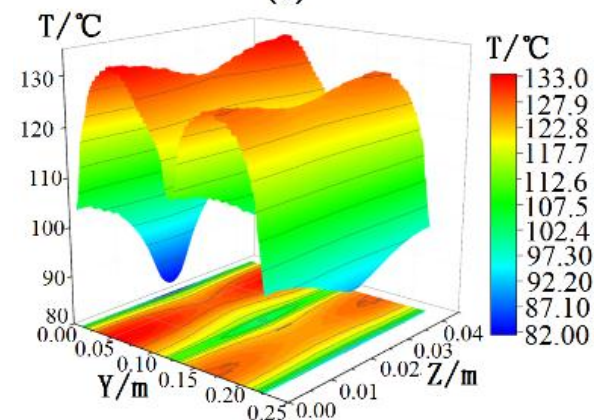

(c)

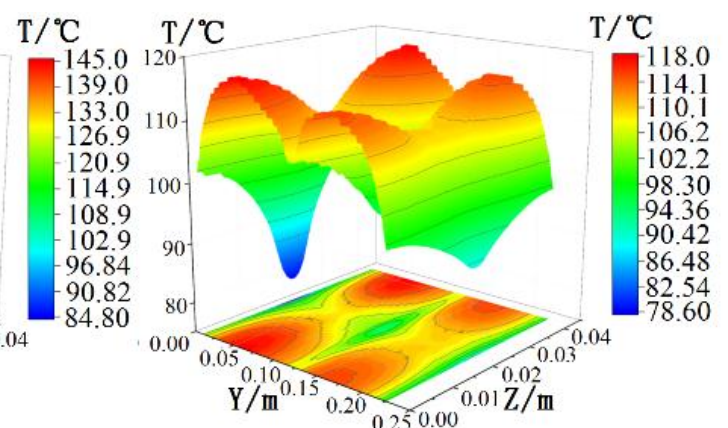

(b)

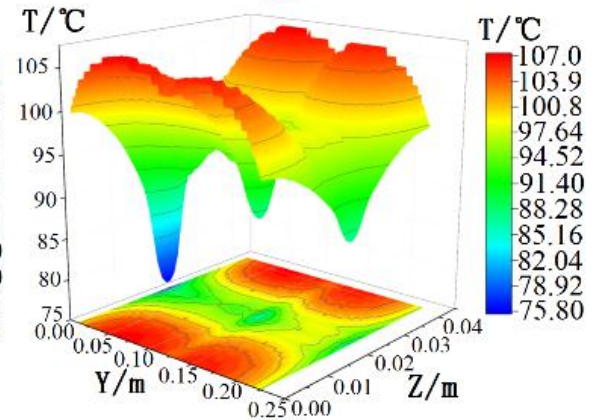

(d)

Figure 8. The main insulation axis-radial temperature distribution in the un-shelling side in the stator main insulation unilateral shelling $\delta=1.0 \mathrm{~mm}$ : (a) The main insulation axial-radial $P_{17}$ temperature distribution; (b) The main insulation axial-radial $P_{18}$ temperature distribution; (c) The main insulation axial-radial $P_{19}$ temperature distribution; (d) The main insulation axial-radial $P_{20}$ temperature distribution.

From Figure 8, it can be seen clearly that the main insulation temperature of the un-shelling side changes along the circumference direction in the case of the main insulation unilateral shelling $\delta=1.0 \mathrm{~mm}$. The maximum value is $145{ }^{\circ} \mathrm{C}$ on the surface $P_{17}$, and the minimum value is $75.8{ }^{\circ} \mathrm{C}$ on the surface $P_{20}$. Compared with Figure 6, the trend of the main insulation temperature along the circumference direction is basically the same, but the maximum temperature increases of $5{ }^{\circ} \mathrm{C}$.

Compared with Figures $5-8$, it is found that the temperature difference between the shelling side and the un-shelling side in the main insulation unilateral shelling $\delta=1.0 \mathrm{~mm}$ is larger than that of the unilateral shelling $\delta=0.5 \mathrm{~mm}$. Moreover, with shelling gap increase, the thermal conductivity of the air is only $1 / 10$ of the main insulation, the heat generated by the windings is more difficult to pass through the main insulation in the shelling side. Therefore, the temperature will be further increased, and un-shelling side of the main insulation in effect of the long-term high temperature can lead to the main insulation heat aging, even greatly shorten the un-shelling side of the main insulation life, causing shelling and other accidents. Once both sides of the main insulation are shelled, heat of windings would be more difficult to pass out, which may destroy the main insulation, causing that the windings occur the ground fault, and that the safe operation of the generator has been seriously disturbed.

3.3. Research on the Temperature Distribution of Circumferential-Radial Section under the Main Insulation of Stator Windings Normal Operation and Fault Operation

By analyzing the temperature distribution of the stator main insulation in the axial-radial section, it is found that the main insulation temperature is greatly affected by the ventilation duct. In order 
to further analyze the influence of the ventilation duct on the main insulation temperature, the main insulation temperature distribution along the circumferential-radial section is studied under normal operation and shelling operation at different axial position.

3.3.1. The Main Insulation Temperature Distribution Along the Circumferential-Radial Direction under Normal Operation

The stator main insulation is divided into two parts in the axial direction, $Z=0, Z=21 \mathrm{~mm}$, $Z=42 \mathrm{~mm}$ in the main insulation normal operation. $Z=0$ and $Z=42 \mathrm{~mm}$ are located in the axial center of the stator teeth, $Z=21 \mathrm{~mm}$ is located in the center of the stator radial ventilation duct. The results of the temperature distribution at different axial positions are shown in Figure 9.

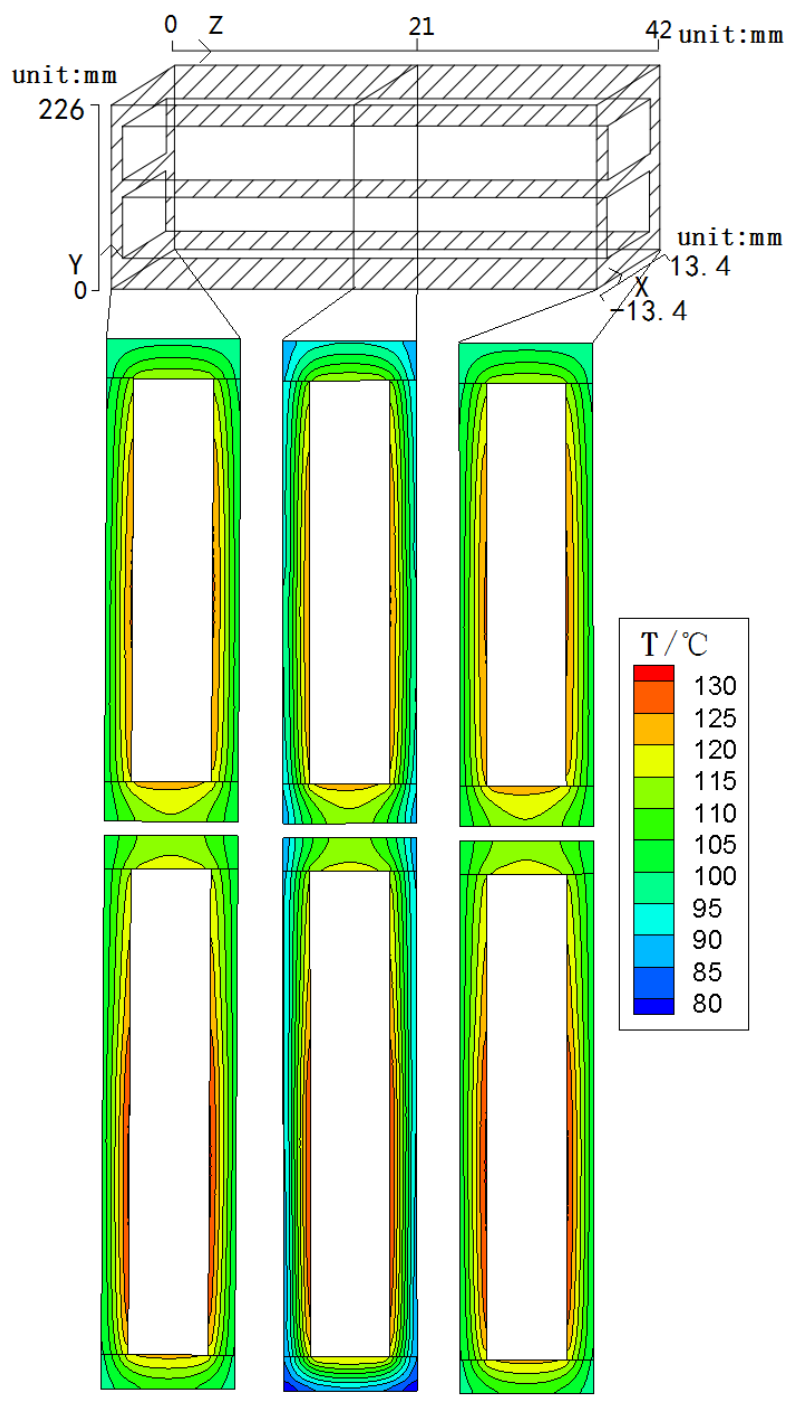

Figure 9. The main insulation temperature distribution along the circumferential-radial section under normal operation.

In Figure 9, the comparison of $Z=0$ and $Z=21 \mathrm{~mm}$ shows that the main insulation temperature of $Z=21 \mathrm{~mm}$ is lower than the main insulation temperature of $Z=0$; the main insulation temperature drop of the stator on the center of the ventilation duct is higher than that of $Z=0$ and $Z=42 \mathrm{~mm}$. This is because that the ventilation duct, better heat transfer, makes the main insulation thermal gradient larger. In addition, the stator core tooth temperature is about $95^{\circ} \mathrm{C}$, the air temperature around ventilation duct is about $70^{\circ} \mathrm{C}$. 
It can also be seen from Figure 9 that the maximum temperature value of the main insulation is $131^{\circ} \mathrm{C}$, appearing near the windings. In addition, the minimum temperature value of the winding insulation is $76^{\circ} \mathrm{C}$, appearing near the stator wedge. However the minimum temperature at the center of the stator core $\mathrm{Z}=0$ and $\mathrm{Z}=42 \mathrm{~mm}$ is $95^{\circ} \mathrm{C}$. This shows that the main insulation of the stator has a large temperature difference in the axial direction, the lowest temperature difference of $19^{\circ} \mathrm{C}$.

3.3.2. The Main Insulation Temperature Distribution along the Circumferential-Radial in the Case of the Stator Main Insulation Unilateral Shelling $\delta=0.5 \mathrm{~mm}$

Based on the above calculation, the main insulation temperature distribution in the center of the stator teeth and the center of the ventilation duct of the calculation area in the case of the stator main insulation unilateral shelling $\delta=0.5 \mathrm{~mm}$ are shown in Figure 10 .

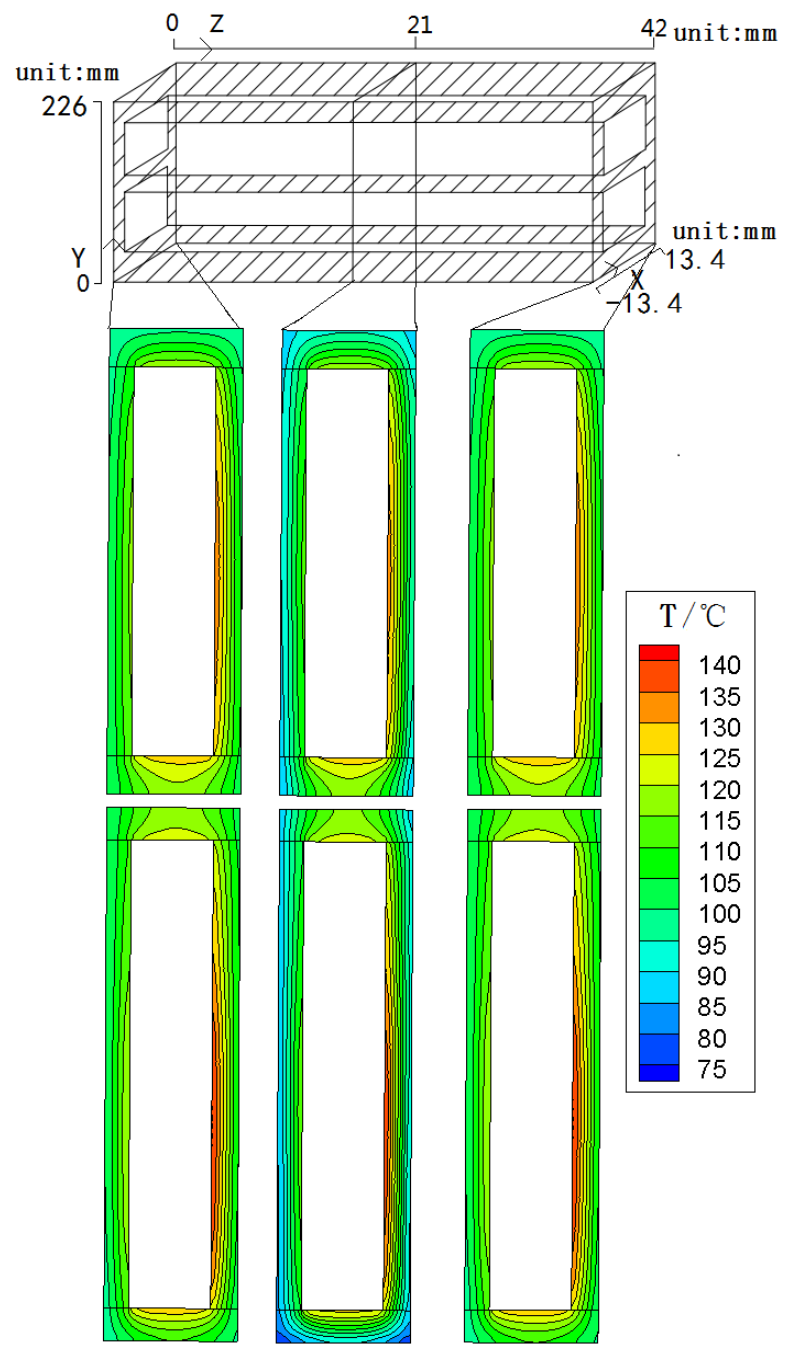

Figure 10. The main insulation temperature distribution along the circumferential-radial in the case of the stator main insulation unilateral shelling $\delta=0.5 \mathrm{~mm}$.

The stator main insulation temperature distribution in the circumferential-radial section is shown in Figure 10 in the case of the stator main insulation unilateral shelling $\delta=0.5 \mathrm{~mm}$. As the shelling gap makes the main insulation thermal conductivity deteriorate, the maximum temperature of the stator insulation increases, but the minimum temperature is still at the stator wedge. Compared to the temperature distribution between the $Z=0$ and $Z=21 \mathrm{~mm}$, the main insulation temperature at the center of the ventilation duct is low. However, due to the effect of shelling gap, in which the air 
undertakes a part of the temperature drop, the temperature distribution of the main insulation in the shelling side is relatively lower than that of the un-shelling side.

Similarly, it is found that the teeth core temperature of the left side is higher than that of the right side, about $5{ }^{\circ} \mathrm{C}$. This is due to the presence of shelling gaps, which leads to inconsistencies in the temperature on both sides of the main insulation.

Compared with the normal operation of the main insulation, the main insulation temperature rise as a whole, the temperature drop of main insulation un-shelling side is larger, and temperature difference of left and right sides also becomes larger.

3.3.3. The Main Insulation Temperature Distribution along the Circumferential-Radial in the Case of Stator Main Insulation Unilateral Shelling $\delta=1.0 \mathrm{~mm}$

$Z=0, Z=21 \mathrm{~mm}, Z=42 \mathrm{~mm}$ temperature field in the case of stator main insulation unilateral shelling $\delta=1.0 \mathrm{~mm}$ are shown in Figure 11 .

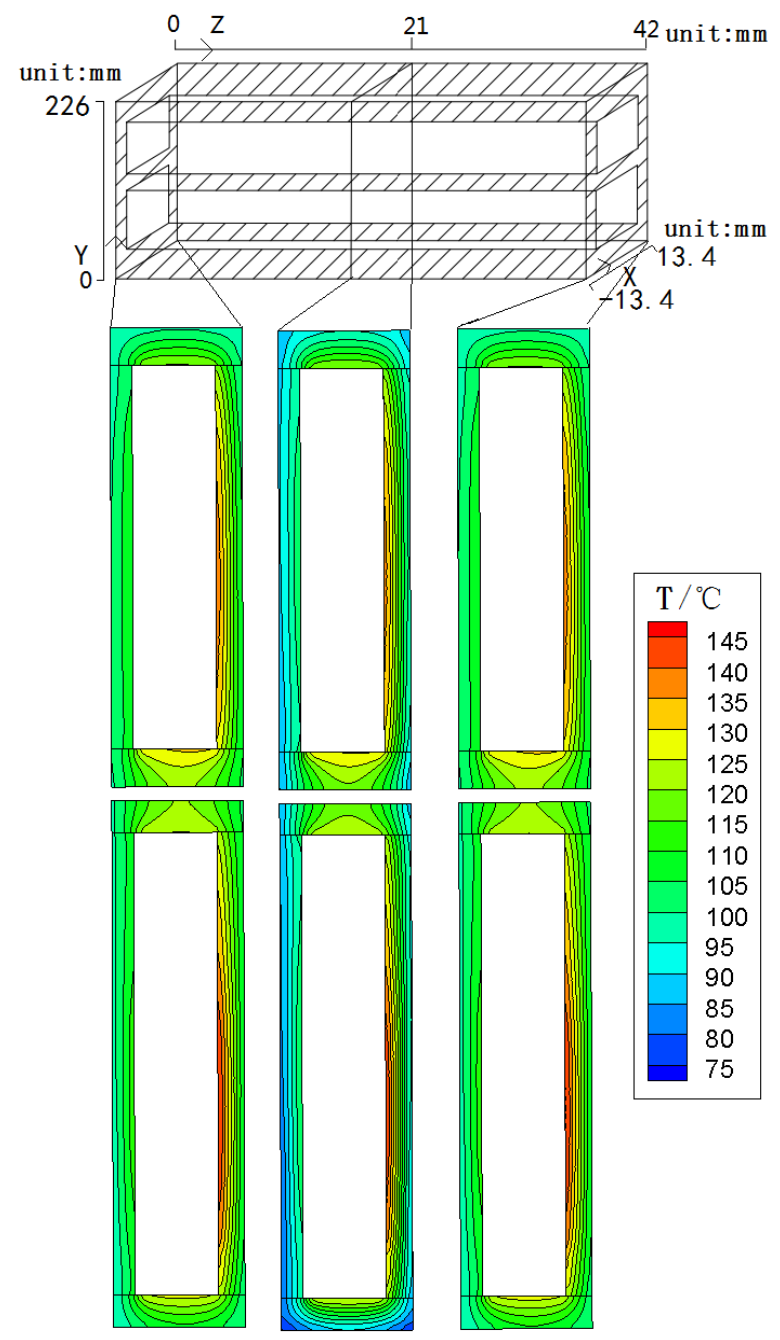

Figure 11. The main insulation temperature distribution along the circumferential-radial in the case of stator main insulation unilateral shelling $\delta=1.0 \mathrm{~mm}$.

The stator main insulation maximum temperature in the case of stator main insulation unilateral shelling $\delta=1.0 \mathrm{~mm}$ further increase of $5{ }^{\circ} \mathrm{C}$ than that in the unilateral shelling $\delta=0.5 \mathrm{~mm}$. The temperature distribution is consistent with Figure 10. 


\section{Conclusions}

(1) In the cases of the main insulation unilateral shelling of the stator, the temperature drop of the main insulation of the shelling side is obviously smaller than that of un-shelling side. With the increase of the shelling gap, the main insulation temperature drop of the shelling side becomes smaller, and the temperature drop of the un-shelling becomes larger, which can lead to bilateral shelling of main insulation considering the thermal aging. The maximum temperature drop of the main insulation is on un-shelling side of the upper winding after the unilateral shelling occurs.

(2) The temperature difference of the main insulation between the upper bar and lower bar close to the stator windings is obvious, but the temperature difference is basically the same in the side of the tooth under main insulation normal operation and fault operation. As the main insulation unilateral shelling gap becomes larger, the maximum temperature value of the main insulation increases, and the maximum, minimum and difference of the temperature in the main insulation shelling side are reduced. The main insulation has a lowest temperature close to the ventilation duct, which is $20^{\circ} \mathrm{C}$ lower than that of the lowest temperature in the center of the stator teeth

(3) In the case of main insulation unilateral shelling of the stator, the minimum temperature close to the core teeth in the shelling side and un-shelling side is different, about a difference of $5^{\circ} \mathrm{C}$. Therefore, it can be effectively monitored and determined the situation of the main insulation overheating and shelling by installing temperature measurement components in the both sides of stator core close to the main insulation.

Author Contributions: Yong Li and Weili Li conceived and designed the experiments; Ying Su performed the experiments; Wenmao Liu and Purui Wang analyzed the data; Yong Li contributed analysis tools; Ying Su wrote the paper.

Acknowledgments: We received funds for covering the costs to publish in open access, which name is "Research on main insulation fault mechanism of air cooled turbo-generator stator" and which number is E17JB00290.

All sources of funding of the study should be disclosed. Please clearly indicate grants that you have received in support of your research work. Clearly state if you received funds for covering the costs to publish in open access.

Conflicts of Interest: The authors declare no conflict of interest.

\section{References}

1. Romary, R.; Demian, C.; Schlupp, P.; Roger, J.Y. Offline and Online Methods for Stator Core Fault Detection in Large Generators. IEEE Trans. Ind. Electron. 2013, 60, 4084-4092. [CrossRef]

2. Nadarajan, S.; Panda, S.K.; Bhangu, B.; Gupta, A.K. Hybrid Model for Wound-Rotor Synchronous Generator to Detect and Diagnose Turn-to-Turn Short-Circuit Fault in Stator Windings. IEEE Trans. Ind. Electron. 2015, 62, 1888-1900. [CrossRef]

3. Yamin, L.D.B.; Shaoyu, W. The Influence of Insulation Aging on Stator Temperature Rise. Large Electr. Mach. Hydr. Turbine 1988, 6, 25-38.

4. Istad, M.; Runde, M.; Nysveen, A. A Review of Results from Thermal Cycling Tests of Hydro-Generator Stator Windings. IEEE Trans. Energy Convers. 2011, 26, 890-903. [CrossRef]

5. Sumereder, C.; Weiers, T. Significance of Defects Inside In-Service Aged Winding Insulations. IEEE Trans. Energy Convers. 2008, 23, 9-14. [CrossRef]

6. Kumar, P.G.S.; Reddy, K.M. Condition Evaluation of Stator Winding Insulation of Vintage High Voltage Turbine Generator. In Proceedings of the 2015 IEEE International Conference on Electrical, Computer and Communication Technologies, Coimbatore, India, 5-7 March 2015; pp. 1-6.

7. Provencher, H.; Hudon, C.; David, E. Thermal and Thermo-Mechanical Aging of Epoxy-Mica Insulated Stator Bars. In Proceedings of the 2013 IEEE Electrical Insulation Conference, Ottawa, ON, Canada, 2-5 June 2013; pp. 248-252.

8. Stone, G.C.; Lyles, J.F.; Braun, J.M.; Kaul, C.L. A Thermal Cycling Type Test for Generator Stator Winding Insulation. IEEE Trans. Energy Convers. 1991, 6, 707-713. [CrossRef] 
9. Tanaka, K.; Kojima, H.; Onoda, M.; Suzuki, K. Prediction of Residual Breakdown Electrical Field Strength of Epoxy-Mica Paper Insulation Systems for the Stator Winding of Large Generators. IEEE Trans. Dielectr. Electr. Insul. 2015, 22, 123. [CrossRef]

10. Brütsch, R.; Tari, M.; Froehlich, K.; Weiers, T.; Vogelsang, R. Insulation Failure Mechanisms of Power Generators. IEEE Electr. Insul. Mag. 2008, 24, 17-25. [CrossRef]

11. Zhu, H.; Morton, C.; Cherukupalli, S. Quality Evaluation of Stator Coils and Bars under Thermal Cycling Stress. In Proceedings of the Conference Record of IEEE International Symposium on Electrical Insulation, Totonto, ON, Canada, 11-14 June 2006; pp. 384-387.

12. Zhu, H.; Kung, D.; Cowell, M.; Cherukupalli, S. Acoustic Monitoring of Stator Winding Delaminations during Thermal Cycling Testing. IEEE Trans. Dielectr. Electr. Insul. 2010, 17, 1405-1410. [CrossRef]

13. Stone, G.C.; Stranges, M.K.; Dunn, D.G. Common Questions on Partial Discharge Testing: A Review of Recent Developments in IEEE and IEC Standards for Offline and Online Testing of Motor and Generator Stator Windings. IEEE Ind. Appl. Mag. 2016, 22, 14-19. [CrossRef]

14. Stone, G.C.; Boulter, E.A.; Culbert, I.; Dhirani, H. Electrical Insulation for Rotating Machines: Design, Evaluation, Aging, and Repair, 2nd ed.; Wiley Press: New York, NY, USA, 2004; pp. 180-192. ISBN 978-1118057063.

15. Stone, G.C.; Warren, V. Effect of Manufacturer, Winding Age and Insulation Type on Stator Winding Partial Discharge Levels. IEEE Electr. Insul. Mag. 2004, 20, 13-17. [CrossRef]

16. Griffith, G.; Tucker, S.; Milsom, J.; Stone, G. Problems with Modern Air-Cooled Generator Stator Winding Insulation. IEEE Electr. Insul. Mag. 2000, 16, 6-10. [CrossRef]

17. Stone, G.C.; Chan, C.; Sedding, H.G. On-Line Partial Discharge Measurement in Hydrogen-Cooled Generators. In Proceedings of the 2016 IEEE Electrical Insulation Conference, Montreal, QC, Canada, 19-22 June 2016; pp. 194-197.

18. Jin, H.Y.; Li, W.L.; Ma, X.H.; Ding, S.Y. Calculation and Analysis of Fluid velocity and Fluid Temperature in Large Air-cooled turbo-generator stator. Proc. CSEE 2006, 26, 168-173. [CrossRef]

19. Li, W.; Ding, S.; Zhou, F. Diagnostic Numerical Simulation of Large Hydro-Generator with Insulation Aging. Heat Transf. Eng. 2008, 29, 902-909. [CrossRef]

20. Li, W.; Hou, Y. Heating Analysis of Stator Strands of Large Hydro-generator Based on Numerical Method. Proc. CSEE 2001, 21, 115-1186. [CrossRef]

(c) 2018 by the authors. Licensee MDPI, Basel, Switzerland. This article is an open access article distributed under the terms and conditions of the Creative Commons Attribution (CC BY) license (http:/ / creativecommons.org/licenses/by/4.0/). 